\title{
Integrity of the Text as a Factor of the Information Message of Pupils
}

\author{
Sergei Vasilievich Yurtaev \\ Department of Theory and Methodology of Primary and Preschool Education, State Humanitarian and Technological University, \\ Orekhovo-Zuevo, Russia
}

Email address:
yurtaev1961@mail.ru

\section{To cite this article:}

Sergei Vasilievich Yurtaev. Integrity of the Text as a Factor of the Information Message of Pupils. American Journal of Data Mining and Knowledge Discovery. Vol. 6, No. 1, 2021, pp. 1-8. doi: 10.11648/j.ajdmkd.20210601.11

Received: April 14, 2021; Accepted: April 30, 2021; Published: June 30, 2021

\begin{abstract}
The purpose of the study, the results of which are presented in this article, was to prove the position that the integrity of the text is a factor in the speech message of schoolchildren. Achievement of this goal became possible through the solution of tasks, which are reduced to the definition of the text, its main features, to the conduct of a pedagogical experiment. The pedagogical experiment involved the collection, quantitative and qualitative processing of essays about a case from life. Such compositions have undergone quantitative and qualitative processing over time, over the course of five years. The temporal analytical approach made it possible to identify the changeable and transient, permanent signs of the speech message of schoolchildren. In the article, the integrity of the text is defined as a feature associated with the location of the nominative forms (sp). The author of the article divides these forms into nominative monosemantic grammatical forms (NMGF) and nominative polysemantic grammatical forms (NPGF). He describes the arrangement of these forms, noticed by him in the process of expressing thoughts by the same schoolchildren at the age of eleven or sixteen. The location of the forms, noticed by the researcher. are subject to grouping, since they are transitory, repetitive. This nature was the reason for the selection of their three groups of location. NMGF, NPGF can be located contact-distant, contact, distant, creating conditions for other textforming features. According to the author of the article, the adjacent text-forming potential of the differentiated dissemination of the integrity of the text affects the dissemination of information, its volume in interconnected predicative units, and the designation of the declared information.
\end{abstract}

Keywords: Text Skills, Integrity of the Text, Text Space, Arrangement of Grammatical Nominative Forms, Nominative Monosemantic Grammatical Forms, Nominative Polysemantic Grammatical Forms

\section{Introduction}

In modern conditions of human interaction, text is becoming increasingly important as a means of this interaction. The result of speech communication largely depends on how high-quality the text will be. Text as a means of verbal communication is an emerging product. To ensure the processes of its successful formation, conditions are created for special education, for example, in schools.

The process of formation of textual skills in schoolchildren is becoming educational guidelines for modern education. In addition, the issues of the formation of textual skills in schoolchildren are the subject of special training for future teachers $[1,17]$.

For a long time, in linguo-methodological research on teaching the Russian language, the question of speech skills that schoolchildren had to master was developed. In this case, linguistic methodologists used psycholinguistic models of speech generation. In particular, the researchers took into account the speech generation models developed on the basis of the activity approach to understanding the speech of such scientists as L. S. Vygotsky. [4], Luria A. R. [12], Zhinkina N. I. [6], Leontyeva A. A. [10], Akhutina T. V. [3] and others.

From the point of view of the activity approach, speech generation is a structured process consisting of a number of stages arranged in a certain sequence. This sequence, as a rule, begins with a speech concept, continues in building a communicative and cognitive program. Further stages are associated by psycholinguists with semantic, superficial syntax, later on there is a grammatical and semantic 
realization of thoughts.

On the basis of speech generation models, classifications of speech skills of Ladyzhenskaya T. A., Kapinos V. I., Soloveichik M. S., Lvov M. R. were compiled.

Ladyzhinskaya T. A. highlights seven speech skills. The first two are the ability to determine the scope of the content and the boundaries of the topic, to subordinate the presentation of the material to the main idea. The other two skills are to collect material for an essay, put it in order, organize it. The next two skills are to build essays of different types, as well as express thoughts accurately, correctly and as brightly as possible. The last, seventh speech skill is to improve what is written [9].

V. I. Kapinos proposes to provide for the ability to navigate in a situation of communication, to establish the motives of speech, its conditions and tasks [8].

Soloveichik M. S. suggests teaching speech in the form of two interrelated directions: 1) improving the actual speech activity (speaking, writing, listening, reading); 2) the formation of individual speech skills that create the basis for enriching speech activity. Improving speech activity involves honing the whole complex of speech skills as a whole, since for its implementation it is necessary to perform all speech actions. That is why the first direction of teaching speech relies on the second, continues and closes it. The second direction provides for the development of particular actions carried out at various stages of speech activity, i.e. the formation of individual speech skills.

Soloveichik M. S. divides speech skills into two groups. One of these groups is the skills needed to create a statement. In her opinion, a student should be able to navigate in a communication situation. He plans the content of the statement, realizing its topic, outlining the course of development of thought, possible micro themes. In addition, he implements the planned plan, formulates thoughts, observing language norms. If necessary, makes changes, corrects what is said or written [16].

Lvov M. R. the classification of speech skills extends to coherent speech. Here are the skills he offers to form: the ability to understand, comprehend the topic, subordinate the content to the topic and concept; ability to collect material; ability to plan work; prepare language tools; compose the entire text; the ability to improve what is written [12].

However, we believe that speech skills are not identical to text skills. Text skills are derived based on the differentiation of the concepts of "language", "speech", "text". Their classification takes into account the data obtained in the study of the text. In addition, we believe that the features of the text can be clarified in the process of studying the processes of giving the expression its features by various groups of people, including schoolchildren.

\section{Materials and Research Methods}

The initial analytical material was, on the one hand, the works of linguistic methodologists, linguists on text theory, on the other hand, the texts of the works of the same schoolchildren aged eleven to sixteen years old.

The works of scientists on the theory of the text became the basis for determining its features, for isolating the main features from them. The results of the analysis of these works served as a guideline for the model created by the researcher and achieved by schoolchildren as they grow up. In addition, these works made it possible to single out the prevailing points of view on the features of the text and to accept the points of view indicated by the researcher as opposed to the point of view belonging to the researcher himself.

The texts of the same schoolchildren at the age of eleven to sixteen years old were obtained by the researcher as a result of conducting an essay lesson on the same topic during the growing up of schoolchildren, in the fifth or ninth grades. The results described below were the result of an artificial life situation, a situation created by the teacher in the lesson of writing an essay about a life incident.

This lesson was preceded by a lesson in working on the presentation of educational text. For five years (from the fifth to the ninth grade) the same educational text "An Unusual History" (after V. Telpugov) was offered. To stimulate its perception, a question was formulated aimed at probabilistic prediction of content. The question was preceded by a short message from the teacher. After reading the educational text, the teacher conducted a conversation tracing the development of cause-and-effect relationships, focused the students' attention on comprehending micro themes, conducted grammar and spelling training, formulated the task: "Write a detailed presentation according to an independently drawn up plan. And so that each part you titled would be highlighted in a paragraph. "

A similar sequence of work was preserved in the lesson of writing an essay. For five years (from the fifth to the ninth grade), a topic was proposed, the source of material for the disclosure of which was the recollections of students about a life incident. At the beginning of the lesson, the teacher strove to evoke the students' impression based on what they saw and heard once. He strove to help schoolchildren find a starting point for expanding their thoughts, He directed schoolchildren to isolate semantic parts into paragraphs, to establish a correspondence between the number of points in the plan and the number of semantic parts.

Thus, the task of the teacher became the product of the motive of the students' speech in the experimental lessons. And her motive was their desire to tell about a case from life. This desire was deliberate. Therefore, it appeared as the goal of the speech.

When working with research material, the following research methods were used:

1. Theoretical text modeling. A method of constructing a concept based on an analysis of various points of view on the definition of this concept, including also the author's understanding of it, which developed in the course of analytical work on understanding the processes of constructing a text by schoolchildren.

2. Accentologization of the essential features of the modeled concept. A method of abstraction, which involves 
taking into account individual essential features that are taken into account by the researcher in the description of the processes under study. For example, taking into account the imparting of the wholeness of the text to the statement in the process of its construction.

3. Modeling the process of constructing text. A way of describing the process of constructing a text through taking into account its main features, actions performed by schoolchildren in order to express thoughts grammatically.

4. Grammatical scaling. A way to digitally designate the order of sentences in a text space. Each sentence was numbered according to its order in the text of the student's composition.

5. Nominative spatial and linguistic analysis of the text of the composition of the maturing schoolchild. A method of text analysis, according to which, from each sentence of the text of a student's essay, the forms of the nominative case (sp) were written out as they were arranged in the order of expression of thoughts. In addition, the places of their use by schoolchildren in the text of the essay were indicated. Separate form of I. p. with its place of use by schoolchildren in the text of the essay was recorded on a separate card.

6. Semantic spatial grouping of nominative word forms. A method of combining grammatical forms, taking into account the commonality of their denotative meaning and places where schoolchildren use nominative forms in the text space. Such a combination led to the formation of nominative groups of words according to the generality of their meaning, indicating the place of these forms in the text. Thus, the nominative forms of the same meaning took on text positions.

7. Genetic method. A way of comparing subsequent research results with previous research results as the same student grows up. The changes occurring in the arrangement of nominative forms of the same meaning in the text space of the composition of schoolchildren were compared.

\section{Research Results}

\subsection{Linguo-Methodological Interpretation of the Text}

In the scientific literature on the methodology of teaching the Russian language, when defining a text, its external side is taken into account, or its speech and linguistic affiliation is recognized, or the text is defined as a product of speech activity.

In the book by E. N. Nikitina "Russian speech" was given the following definition: "A text is a combination of sentences related in meaning and grammar" [15]. This definition, of course, is permissible, it fixes the fact: the text consists of sentences. But from the point of view of the person who creates it, sentences that are not grammatically connected with other sentences are possible, breaks in a group of sentences are possible, and repetitions of the same sentences are possible.

The recognition of the speech and language belonging to the text is contained in the book by N. A. Ippolitova "Text in the system of teaching the Russian language at school." It is a unit of speech because it is a specific speech work, which is manifested most often in writing, but also in oral form. It is a unit of language because in teaching we use different models of texts, reproduced partially or completely at various stages of analysis and interpretation [7].

This definition certainly reflects the speech and linguistic nature of the text. It contains an indication of the connection of two entities in it. However, from the point of view of the person who creates the text, the text appears as the resulting product. This product is obtained as a result of the implementation of speech acts through language.

Defining a text as a sequence of sentences, as a unit of language, speech, scientists strive to highlight the norms of its construction: the presence of a semantic, grammatical connection between sentences, the correspondence of the content of the text to its name (title), completeness in relation to the title (title), literary processing, purposefulness.

According to M. R. Lvov, "the text is a product of speech activity", "the space of utterance, the field of expression of thought. Within this space, a speech strategy is being developed, formed" [14].

Consequently, the text is created in one of the types of speech activity, in particular, in written speech. Therefore, the text is her work. Works of written speech include works of fiction, scientific, publicistic works, works of oral folk art, monuments of ancient chronicles, official business documents, legal laws, i.e., everything that can be recorded using a graphic code, including number, student expositions, essays.

The term "written speech" is broader than the term "text". The first term means the process of generating speech, its mechanisms, in some branches of science, for example, in literary criticism, its interpretation expands even more and affects the formation of the worldview of writers, poets, and their creativity in general. At the same time, it should be understood as the linguistic fabric of expressed thoughts that arises in the process of speech acts. The second term denotes the linguistic fabric of the work.

Thus, a text is a product of speech activity generated during the operation of speech mechanisms, in the process of manifestation of speech acts, obtained in the form of a speech product alienated from its author. This work, in the process of its creation, acquires its characteristic features. It consists of syntactic units that are more extensive than the sentence.

\subsection{Integrity as the Main Feature of the Text}

The features of the text represent the stages in the cognition of its ontological, epistemological, structural features. There is no generally accepted limited list of them in the scientific literature. Some authors have it more detailed, others less detailed. In the methodology of teaching the Russian language, along with other branches of science, preference is given to several features of the text.

So, for example, N. A. Ippolitova. ON THE. writes that integrity is manifested in the unity of the theme. Its development is carried out by changing predication. The 
means of expressing integrity are the repetition of key words, the identity of reference (the correlation of these words with the same object of reality), situational connections, person, time, mood of the verb [7].

The interpretation of $\mathrm{N}$. A. Hippolytic integrity is supplemented by A. A. Leontyev. According to A. A. Leont'ev, its essence lies in the hierarchical organization of plans (programs) of speech utterance [11].

Undoubtedly, the illuminated feature of the text serves as a feature of its internal content, a feature that has external expression. However, the disclosure of the topic is associated with the development, first of all, of the subject and semantic content, with the grammatical manifestation of both. Following the views of I. R. Halperin, we believe that the subject content provides information about facts, events, processes, the semantic content expresses the author's attitude to these phenomena [5].

The dissemination of subject content in the text space is the essence of the feature called the integrity of the text.

According to N. D. Arutyunov, the position of the subject in the sentence is associated with the identification of objects of reality [2]. The subject is indicated mainly by the nominative case (ip).

Consequently, the subject content is expressed by these forms. Taking a certain position, forms etc. are one of the indicators of the integrity of the text.

\subsection{The Location of the Nominative Case Forms in the Text Space of the Composition of Schoolchildren}

\subsubsection{The Concept of the Positional Arrangement of Forms, etc.}

Just as the minor members of a sentence can be located at a distance in relation to the main members of a sentence, the forms of etc. are located in predicative units, following one after another in a certain order. Thus, they have a position. The position for such forms will be considered their place in the order of the predicative units. In this case, the number of positions in one composition coincides with the number of predicative units. And each next position falls on the ordinal number of each next predicative unit.

To illustrate the place of use of the forms I. p. let's use an example. For this we take the essay of Natasha V. for the seventh grade. We indicate below the positions of the forms of interest to us. These are the forms, their position numbers:

I: 3, 15, 27, 30, 31, 32; asterisks: 12, 13, 20, 34; ball (he): $8,9,10,11$; flashlight: 5 , 6; twelve: 2 ; flash: 18 ; all: 19 ; we: 26; none: 28; all: 29; ash: 33; an asterisk (one of them): 14 , 16; smell (s): 21, 23; something: 4, 22; history: 1, 35; this (meaning "fall"): 17; light: 7, 25; mom: 24.

Let us write down predicative units containing the forms indicated above.

..., I went out onto the balcony.

...I was scared.

....and I told everything.

..., I could not sleep for a long time. I remembered what had happened.

...When I went to get some bread...
..., there small, red stars fell to the ground. Then the stars began to fly from everywhere.

...Only the stars, which had not yet fallen, reached the ground.

...where the stars fell,...

...Meanwhile, the balloon was swelling and swelling. It swelled so much that it occupied the entire roof, and where it went beyond,...

...A small red flashlight appeared over the neighboring house. It got bigger and bigger.

...When it struck twelve,...

...Then there was a flash...

and everything disappeared.

...We returned to the room,...

...But nobody believed me.

When everyone went to bed...

...there were ashes in those places,...

...One of them flew to our carpet...This star burned a hole in the carpet.

...The smell was like that...Then it was replaced by a pleasant, fresh, New Year's aroma.

...Suddenly something flashed......as if something was burning.

This story happened to me on New Year's Eve...This is the story that happened to me on New Year's Eve.

...This lasted five to six minutes.

...In our and in this house, the lights went out...The lights immediately came on.

...Mom lit a candle and went out onto the balcony.

Among the forms of I. p. there are forms of the same meaning. Let us call such forms nominative monosemantic grammatical forms (NMGF). NMHF are found in predicative units, following each other and at a distance from each other, in the group of predicative units. These forms have contactdistant, contact, distant positions.

\subsubsection{Contact-Distant Locations of the I. p. Forms}

Contact-distant positions of the NMHF are their locations in interrelated predicative units, following each other and at a distance from each other. In such positions, their arrangement is continuous-discrete.

Let's show the digital expression of the changes in these positions: Grade 5 - 11.3; Grade 6 - 7.2; Grade 7 - 15.3; Grade 8 - 13; Grade 9 - 21.4. The dynamics of development has a spasmodic behavior. In the sixth and eighth grades, we see recessions. In the fifth, seventh, ninth grades, the analyzed volume increases.

In percentage terms, the share of this species is as follows: 5th grade - 49.3; Grade 6 - 37.4; Grade 7 - 49.6; Grade 8 34; Grade 9 - 49.5. Its dynamics reflects quantitative changes. This share is predominant.

HMGF, having distant positions, can occupy in relation to HMGF, having contact positions, pre-position, post-position, interposition.

Here are some examples of the named locations.

Preposition of distant location.

...like doves warming themselves at a well. (eight)... 
...They did not come close, but ate at a distance. (11, 12)...(Grade 5, Sergey Z.)

Distant position postposition.

...The first thing I did was toss the fishing rod, and then I went to change. And when I came for a fishing rod, I saw. (4, $5,6,7) \ldots$

..., and began to pull again. (nine)...

....and I called my grandfather. (eleven)...

...And when I gave him a fishing rod, (19)...

...as I took it off the hook. (23)...(Grade 6, Kolya L.)

Distance position interposition.

I was a witness to the story that I now want to tell. (12)...

...I went to my brother a long way. (6)

...but I didn't know what it was about. Then I realized. (15,

16)...(Grade 7, Sergey Z.)

Pre-, postposition of distant location.

..., then the grandfather immediately abandoned the fishing rod. (3)...

...And then the grandfather swam on it for a fishing rod.

He began to drag a fishing rod to the boat, $(19,20) \ldots$

..., then he swam for a fishing rod without a boat, (22)...(5th grade, Kolya L.)

Pre-, interposition of distant location.

...Father took the frames and went to the boat, (15)...

...Having submitted the frames, he climbed into the boat, (17)...

...Father unwound one frame and put it near the dried reeds, (19)...

...Taking out the second frame from the case, unwound it

too. He leaned over to the side of the boat, $(21,22) \ldots$

...and the father fell out of the boat. (24)...

...Daddy swims well, but he could freeze. $(26,27)$...(Grade

9, Alyosha P.)

Inter-, postposition of distant location.

...Grandma was sitting and reading a book. Suddenly she saw $(20,21) \ldots$

...Later, the elderly woman was able to see the head. She realized $(23,24) \ldots$ 28)...

...and the grandmother was very scared. She thought (27,

...But a minute later the old woman saw the same face. (thirty)...

...that was lying on a crumbling cot. The old woman told

her tragic story. $(37,38) \ldots$

...to make her die. (41)...(Grade 9, Ira I.)

Pre-, inter-, postposition of distant location.

One summer day I arrived in the village. (one)...

...to which I came. When I was walking in the garden, I heard a hiss. $(3,4,5) \ldots$

...I didn't pay attention at first. (eight)...

...I looked into the well with fear. And I saw there a big

hedgehog with little hedgehogs. $(10,11) \ldots$

...I called my dad. (14)...(Grade 5, Lena T.)

Among the options for the contact-distant location of the NMHF, there is a progressive increase in the number of positions, the proportion of their pre-, interpositional location. The increase in positions with recessions concerns the pre-, inter-, post-positional arrangement of these forms. The latter location is dominant in the ninth grade.

In pre-, inter-, post-position, the central subject of speech is most often formed grammatically.

\subsubsection{Contact Locations of Forms, etc.}

Contact positions of the NMHF are their locations in predicative units, following each other. Their difference from contact-distant positions is the absence of a position located at a distance from the position or from the positions of any NMHF

Quantitative changes in these positions are as follows: Grade 5 - 4.7; Grade 6 - 5.3; Grade 7 - 7.3; Grade 8 - 11.5; Grade 9 - 10.7. There is one recession here. He is in the ninth grade. Therefore, the number of positions increases progressively, but at the end of secondary school, it regresses.

In percentage terms, the dynamics of changes in the number of positions takes the following form: 5th grade 22.5; Grade 6 - 30; Grade 7 - 25.1; Grade 8 - 33; Grade 9 26.8. Their share either increases or decreases. It is intermittent. Among the three types of positions, the leading position is inferior to contact-distant positions.

Let us give examples of the contact location of the NMHF.

Location in a group of predicative units.

...We went for a walk. We walked without a teacher. (4, 5)...(Grade 5, Lena G.);...It turns out that grandfather, when he got up at night, saw the open door, he took it and closed it. $(24,25,26)$...(Grade 8, Katya M.); Once we went to the village. When we arrived, $(1,2) \ldots($ Grade 6 , Julia B.);... and I went to the Urals. I washed it and didn't ride in the mud anymore. I went to my brother, $(9,10,11)$...(Grade 6 , Sergey Z.)

In the group of predicative units, predominantly accompanying objects of speech are formed.

To nominative forms located in contact, we also include forms that have different meanings, but affect the unity of thoughts of predicative units located nearby. We will call such forms nominative polysemantic (NPGF).

NPGFs are located in the predicative unit of a complex sentence or in a simple sentence.

The location of the NPGF in the predicative unit of a complex sentence.

...Now the weekend has come, and we went to rest. (3)...(Grade 8, Lena G.);...The doctor said she would be walking soon. (18)...(Grade 5, Oksana Sh.);...Then we noticed that the beast had a white speck on its forehead. (35)...(Grade 7, Katya M.);...Then the doorbell rings, Vaska with huge eyes says: (2)...(Grade 6, Zhenya G.);...Suddenly a strong wind blew, clouds flew in instantly. $(10,11)$...(grade 8 , Kolya L.);... Once, when I was climbing the path to the top, I saw that small cracks appeared between the squeezed stones, and from these cracks tender, yellow flowers began to sprout. (15)...(Grade 7, Tanya K.)

NPGF location in a simple sentence.

...But, passing through the plot, we heard some strange and distant sounds. These sounds came closer and closer. (32)...(Grade 9, Katya M.);...My sister Oksana and I wanted 
to drink and bought ice cream, but it was sweet, we wanted to drink even more. And the money ran out. (13)...(Grade 5, Masha M.);...The results surprised the residents of the city. The boy didn't have a scratch, (20)...(Grade 8, Ira I.);...Mom asked: "What's the matter?" (16)...(Grade 9, Zhenya G.)

Among the options for the contact location of nominative grammatical forms, the number of NPGF positions in the composition of complex, complex sentences increases. However, the proportion of these locations fluctuates. Starting from the seventh grade, the proportion of positions in a simple sentence, associated with other predicative units using lexical and grammatical means, prevails.

In the predicative unit of a complex sentence or in a simple sentence, single objects of speech are formed.

\subsubsection{Distant Positions of the Forms I. p.}

Distant positions of the NMHF are their locations in predicative units at a distance from each other. The minimum number of these positions is two positions. They differ from other positions in the absence of NMHFs located in predicative units following each other.

Quantitative changes in these positions are as follows: Grade 5 - 2.7; Grade 6 - 4.5; Grade 7 - 4.6; Grade 8 - 6.2; 9 grade 4.6. There is a recession here. He is in the ninth grade. This development dynamics is similar to the development dynamics of contact positions.

The percentage of these changes is as follows: Grade 5 12.1; Grade 6 - 21.4; Grade 7 - 14.3; Grade 8 - 19.2; Grade 9 - 10.6. The proportion of distant positions is wavy. It undergoes increasing and decreasing. Its percentage is the lowest in all grades.

Let's move on to illustrating the options for the distant location of the NMHF.

Location in predicative units one position apart.

1. Subjects of speech are drawn up in two positions:

...I agreed...There I put all my accessories: books, a fishing rod, a diving mask. $(4,6) \ldots(6$ th grade, Dima Z.);...This story happened to me and my brother in the summer in the village...This is the story. $(1,3) \ldots($ Grade 8 , Katya M.);...A girl named Ritsa was in love with a young man...The girl could not bear the separation and threw herself down from a high mountain. $(45,47)$...(Grade 8 , Masha M.);

...Uncle Pasha went to the car...and he fell on his car. (20, 22)...(Grade 8, Lena G.)

...When everyone noticed...they shouted: $(13,15) \ldots(6$ th grade, Sergey Ch.);

...We went to the Urals again,...We took a dip and went home. $(12,14)$...(Grade 6, Sergei Z.);

...After a little time, Mashenka comes running to us with a large crucian carp in her hands and says,... Then she brought another one, and another, and another. $(14,16)$...(Grade 7, Natasha V.);... which became a powerful green wall literally behind the house...First, the forest was our salvation on hot autumn days. (3, 5)...(Grade 9, Katya M.);...This extraordinary story about a boy...That's what it is about. (1, 3)...(Grade 9, Masha M.);

...then she will not touch you...and until she leaves, (19,
21)...(Grade 5, Zhenya G.);...I am very grateful to that person....and I want $(32,34)$...(Grade 9, Sveta L.);

...but suddenly a huge tree falls before her eyes...The tree fell on the hood. $(21,23) \ldots($ Grade 8 , Masha M.);...and then the float went abruptly to the bottom...that the float got caught on something, $(26,28)$...(Grade 7 , Dima Z.);... and the doors were wooden and did not hold well...the doors began to fall and fell on me. (5: 19)...(6th grade, Zhenya L.)

2. Subjects of speech are drawn up in three positions:

...and we started to put on our shoes...We went to school...but we didn't take him. $(16,18,20)$...(6th grade, Andrey I.);...that the guy is picking our lock,...But he continued to pick the lock...But this guy threatened him. (18, $20,22)$...(6th grade, Lena T.);...The cancer was crawling over the bucket,...then it quickly crawled into the water...Even in winter, the cancer reminds us of warmth and light. (30, 32, 34)...(Grade 8, Natasha V.);...My father and I were returning from hockey...until we saw a terrible picture... When we came closer, $(5,7,9)$...(Grade 8, Sergey Z.)

Location in predicative units that are several positions apart.

1. Subjects of speech are drawn up in two positions:

...This hiss came from the well, (6)...But the hiss became more and more. (9)...(5th grade, Lena T.);..., but the pilot did not know it. (13)...The pilot began to request land. (16)...(Grade 7, Ira I.);...I went into the spring forest and was very surprised. (3)...Then I realized. (6)...(Grade 8, Zhenya G.);

...I came closer, (10)...I carefully walked over them, (16)...(Grade 5, Zhenya L.);...as the detachment arrived at the place, (9)...In the morning, the detachment began to gather home. (16)...(Grade 6, Dima Z.);...In the air his skin flew off, (12)...The skin of the plane was torn off. (22)...(Grade 7, Ira I.);...The tenants of the apartments, like ants in an anthill, left the building in fear. (20)...The tenants dispersed to their apartments. (30)...(Grade 8, Sergei Z.);...the boat was already inflated, (14)...and at that moment the boat came across reeds, (23)...(grade 9, Alyosha P.);

This story happened to me on New Year's Eve. (1)...This is the story that happened to me on New Year's Eve. (35) (Grade 7, Natasha V.);...This is the story. (3)...This is the story. (23) (Grade 8, Ira I.); This extraordinary story happened to me and my friends in the village. (1)...This is the story. (53) (Grade 9, Katya M.)

2. Subjects of speech are drawn up in three to five positions:

...When we came to swim at Kumachka, (2)...When we came to the place. (5)...Then we went home. (15)...(5th grade, Dima Z.);..., the car is on fire. (12)...how it caught fire, (18)...The car turned black instead of white. (20)...(Grade 6, Ira I.);...when dad catches a fish. (18)...but dad said: (22)...In about fifteen minutes dad pulled the cancer out of the river. (28)...(grade 8, Natasha V.);

Once my mother and I were cleaning the house. (1)...As soon as we got out, (3)...suddenly we heard, (8)...My mother and I ran out into the street. (12)...(5) class, Oksana Sh.);...when I went to school for Alyosha, (1)...so that I sat on 
the chair, (6)...I sat on the chair. (8)...I got up from the chair, (13)...(Grade 6, Andrey I.); I saw this extraordinary story with my own eyes. (1)...and I saw (15)...I told my dad, (17)...I told my mother and grandmother. (31)...(7th grade, Andrey I.);

...when I was in the gymnasium, (2)...I went with my friends to the horizontal bar. (6)...I fell on the stones and glass with my forehead. (9)...I lay there for a very long time. (14)...I went with the doctor to the hospital. (16)...(5th grade, Lena G.); Once Daddy took me hunting in the forest. (1)...Daddy found footprints, (56)...Daddy ran after her, (19)...He was holding a fox in his hands, (22)...and Daddy agreed. (27)...(grade 5, Tanya K.); Mom told me this extraordinary story. (1)...Mom went to school. (3)...Mom ran after the girl, (10)...only mom was sitting at a distance from them. (19)...Once mom decided to approach her. (27)...(Grade 7, Masha M.)

\section{Discussions}

In the process of imparting integrity to the text of an essay about an incident in life, a progressive increase in the volume of the forms of i. p. occurs. This expands the positional text field in general. All their diversity can be summarized in two groups: the group of nominative monosemantic grammatical forms (NMGF) and the group of nominative polysemantic grammatical forms (NPGF).

NMHF occupy contact-distant, contact, distant positions.

The contact-distant positions of the NMHF are increasing. But the increase is abrupt. It is in decline.

Contact, distant positions of NMHF increase to the ninth grade. In the ninth grade, their quantitative decline occurs.

As schoolchildren grow older, the number of speech objects that are formed grammatically, in contact-distant, in distant positions of the NMHF, increases to three objects of speech, in contact positions - up to eleven objects of speech.

Contact-distant design of objects of speech is predominant. It is carried out in separate parts of the composition and throughout the text. Its extent depends on the vastness of the positional field of the SP form.

Contact registration is carried out to a lesser extent. It takes place in separate parts of the composition.

Distant decoration is even less common. It is found mainly in two places in the composition. In addition, it is present throughout a certain piece of text or frames it.

Consequently, the hierarchy of objects of speech, logical subjects, is subjected to grammatical design. Its highest level is occupied by the logical subjects of the contact-distant design of the NMHF, the intermediate - the logical subjects of the contact design of the NMHF, the lower - the logical subjects of the distant design of the NMHF.

The subjects of speech are formed contact-distantly in preposition, in postposition, in the interposition of one NMGF in relation to other similar forms. In addition, combinations of these arrangements are possible.

The subjects of speech are formalized in a contact manner in predicative units following each other, in the predicative unit of a complex sentence, in a sentence related to other sentences by meaning. In the first case, the nominative grammatical forms are monosemantic, in the other two, they are polysemantic.

The subjects of speech are formed distantly in predicative units located at a distance of one or several positions.

Among the options for the contact-distant location of the $\mathrm{NMHF}$, there is a progressive increase in the number of positions, the proportion of their pre-, interpositional location. The increase in positions with recessions refers to the pre-, inter-, post-positional arrangement of such forms. The latter location is dominant in the ninth grade.

Among the options for contact location, the number of NPGF positions in the composition of complex, complex proposals is increasing. However, the proportion of these locations fluctuates. It increases and decreases. Starting from the seventh grade, positions prevail in a simple sentence associated with other predicative units using lexical and grammatical means.

Among the variants of distant location, the number of NMHF positions in predicative units, following each other through one position and through several positions, increases. The share of these positions is extremely volatile. She hesitates. Nevertheless, positions in predicative units prevail, following each other through several positions.

LMGF in contact-distant positions express the central, additional objects of speech. The central subject of speech is often formed in the pre-, inter-, postposition of one form, etc. in relation to other such forms, additional objects of speech are often formed in preposition, in postposition.

NMHF in contact (in the group of predicative units) or in distant positions express the accompanying objects of speech.

A group of predicative units or a predicative unit is limited to punctuation marks of semantic completion

- left and right,

- left,

- on right.

Or not limited to that.

By the presence / absence of punctuation marks for the semantic completion of the form etc. are located contact in

- predicative units that coincide with the boundaries of a complex sentence: This is a story that happened to me, and it will be remembered for my whole life;

- in a few simple sentences: Now the mother could hug her child. She pressed his face to her chest; Here in front of the thickets of hazel. These thickets are quieter and cooler;

- simple and complex sentences: Our dog has never seen hedgehogs, and therefore barked loudly. The poor frightened hedgehog, curled up in a ball, snorted incessantly;

- a simple sentence and in the predicative unit of a complex sentence: And we went. When we came to visit,..; Once my friend and I went for a walk. Then we see...; The next day my grandfather called me to the maritime museum. I couldn't even imagine...;...that Kutka killed two chickens. The rest of the way he walked proud;..., my grandmother and I went to the village. My grandmother's sister lived there;...how he put Uncle Gena on track number two. There was a sand embankment on this route. 
People, passing along it, trod the path,...;

- in predicative units of complex sentences:...because my mother tried her best here too. Mom called the teachers and said...

By the presence / absence of punctuation marks for the semantic completion of the form etc. located distantly in

- a simple sentence: This story happened to me at the age of five; We went with mom and dad to visit; First, the children did a warm-up;

- the predicative unit of a complex sentence: She saw,...; I left because...;....and Uncle Seryozha and dad began to pump up the boat;...that the lifeguard fell and crashed because of her,..., she opened my diary and said,...;... we see...

\section{Conclusions}

The integrity of the text can be expressed through the arrangement of the nominative (sp) forms in predicative units, following one after another. This expression is provided by nominative monosemantic grammatical forms (NMGF) and nominative polysemantic grammatical forms (NPGF). Depending on the text position, these two groups of forms, etc. have different locations. They can be located contact - distant, contact, distant.

As schoolchildren grow up, the number of objects of speech, drawn up contact-distantly, contact, distantly increases with recessions in their growth. The dynamics of development is spasmodic. Nevertheless, this dynamics repeats the pattern of the distribution of SP shapes. in the text space.

The growth of NPGFs with a contact location indicates the expansion of informational information. This fact becomes an indicator of the formation of groups of sentences that reveal a single thought. The expansion of the contact location of NPGF gives reason to talk about the complication of the process of expressing thoughts by schoolchildren, about an increase in the number of complex sentences, about the appearance of an increasing number of groups of sentences that are interconnected in meaning.

In order to impart greater stability to the integrity of the text, it is necessary to highlight the corresponding textual skill, which will be formed in schoolchildren in the process of teaching speech generation. In order for this pedagogical work to proceed successfully, it is necessary to keep in mind the following fact: the location of some forms of SP. gives integrity to the text (NMGF, NPGF), the arrangement of others - makes the text less complete. To the second location, we include a separate distant location of the NMHF, interrupting the development of a common meaning and creating prerequisites for the appearance of logical errors. In addition, it is necessary to take into account the fact that the distant location can extend to the NMHF, which is not found in the group of predicative units, but is located in single places at a distance from each other. This location will be potential, based on it, the NMGF may appear, occurring in predicative units following each other.

The work of the teacher in teaching schoolchildren the location of the forms, etc. includes tasks for observing the use of these forms in groups of sentences, for highlighting their general meaning, for preventing logical errors, for developing the content of sentences as separate independent sentences.

\section{References}

[1] Antonova L. G., Zimina L. I. Innovative models of working with text in the classroom with students of philology. Yaroslavl Pedagogical Bulletin. 2018. No. 6. P. 98-10.

[2] Arutyunova N. D. The proposal and its meaning. Moscow: Nauka, 1976. $383 \mathrm{~s}$.

[3] Akhutina T. V. Generation of speech. Neuro-linguistic analysis of syntax. M.: KD Librokom, 2012. 215 p.

[4] Vygotsky L. S. Collected Works. In 6 volumes. V. 2. Problems of general psychology. M.: Pedagogika, 1982. 502 p.

[5] Galperin I. R. Text as an object of linguistic research. M.: KomKniga, 2006. 144 p.

[6] Zhinkin N. I. Psychological foundations of the development of thinking and speech. Russian language at school. 1985. No. 1. P. 47-54.

[7] Ippolitova N. A. Text in the system of teaching Russian at school. Moscow: Flinta: Nauka, 1998. 170 p.

[8] Kapinos V. I. other Development of speech: theory and practice of teaching. M.: Linka-Press, 1994. P. 6-12.

[9] Ladyzhenskaya T. A. Development of speech as a special area of the Russian language methodology. In the book: Methods for the development of speech in the lessons of the Russian language. M.: Education, 1980. P. 4-17.

[10] Leontiev A. A. Speech activity. In the book: Fundamentals of the theory of speech activity / Ed. A. A. Leontyev. Moscow: Nauka, 1974. P. 21-28.

[11] Leontiev A. A. Signs of coherence and integrity of the text. In the book: Linguistics of the text. Issue 103 / Resp. ed. I. I. Chernyshov. M.: Nauka 1976. P. 60-69.

[12] Luria A. R. Language and Consciousness. Moscow: Moscow State University Publishing House, 1998. 335 p.

[13] Lvov M. R. and other Methods of teaching the Russian language in primary school. M.: Publishing Center "Academy", 2013. S. 394-396.

[14] Lvov M. R. Fundamentals of the theory of speech. M.: Publishing Center "Academy", 2000. 245 p.

[15] Nikitina E. I. Russian speech: A textbook for the development of coherent speech. 5-7 grades. Moscow: Bustard, 1994. 190 p.

[16] Soloveichik M. S. Improving the speech activity of junior schoolchildren. In the book: Russian language in primary grades: theory and practice of teaching. M.: Education, 1993. P. 223-339.

[17] Sviridova A. V., Shiganova G. A., Yuzdova L. P. The content of the communicative and linguocultural competences of the future primary school teacher in the course of mastering the categories of the text. Bulletin of the South Ural State Humanitarian Pedagogical University. 2019. No. 4. S. 182-201. 